\title{
Three isolates of novel polyphosphate- accumulating Gram-positive cocci, obtained from activated sludge, belong to a new genus, Tetrasphaera gen. nov., and description of two new species, Tetrasphaera japonica sp. nov. and Tetrasphaera australiensis sp. nov.
}

\author{
A. M. Maszenan, ${ }^{1}$ R. J. Seviour, ${ }^{1}$ B. K. C. Patel, ${ }^{2}$ P. Schumann, ${ }^{3}$ \\ J. Burghardt, ${ }^{3}$ Y. Tokiwa ${ }^{4}$ and H. M. Stratton ${ }^{1} \dagger$
}

Author for correspondence: R. J. Seviour. Tel: +61354 447459. Fax: +61354447476. e-mail: r.seviour@latrobe.edu.au

1 Biotechnology Research Centre, La Trobe University, Bendigo, Victoria 3550 ,

Australia

2 Faculty of Science and Technology, Griffith University, Nathan, Brisbane,

Queensland 4111, Australia

3 Deutsche Sammlung von Mikroorganismen und Zellkulturen $\mathrm{GmbH}$, Mascheroder Weg $1 \mathrm{~b}$, D-38124 Braunschweig, Germany

4 National Institute of Bioscience and HumanTechnology, Ministry of International Trade and Industry, Ibaraki 305, Japan
Two isolates of Gram-positive cocci (Ben 109 and Ben 110) which could accumulate polyphosphate and were microscopically similar in appearance to so-called ' G-bacteria', appearing as tetrads, were isolated from samples of activated sludge biomass by micromanipulation and grown in axenic culture. On the basis of their phenotypic and chemotaxonomic characters and 165 rDNA sequences, these isolates, together with strain $\mathrm{T1}^{-} \mathrm{X7}^{\mathrm{T}}$ isolated and described previously in Japan, belong to a new genus. These isolates are phylogenetically different from Tessaracoccus bendigoensis, Friedmanniella spumicola and Friedmanniella capsulata, Gram-positive cocci isolated previously in this laboratory. They are characterized by type A1 $\gamma$ peptidoglycan, with meso-diaminopimelic acid as the diagnostic diamino acid.

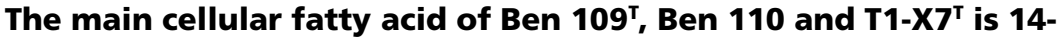
methylpentadecanoic acid ( $\mathrm{i}-\mathrm{C}_{16: 0}$ ). The major menaquinones of Ben $109^{\top}$ are MK-8 $\left(\mathrm{H}_{4}\right)$, with MK-8 $\left(\mathrm{H}_{2}\right)$ and MK-8 in trace amounts. In Ben $110 \mathrm{MK-8}\left(\mathrm{H}_{4}\right)$ and MK-6 $\left(\mathrm{H}_{4}\right)$ are the major menaquinones, while T1-X7' has $M K-8\left(\mathrm{H}_{4}\right), \operatorname{MK-7}\left(\mathrm{H}_{4}\right)$ and MK-6 $\left(\mathrm{H}_{4}\right)$ as its menaquinones. All three contain phosphatidylinositol, phosphatidylglycerol and diphosphatidylglycerol as their polar lipids. These properties, together with $16 \mathrm{~S}$ rDNA sequence data, suggest that they all belong to a single new genus for which the name Tetrasphaera gen. nov. is proposed. However, the lipid, cellular fatty acid profiles and DNA-DNA similarity data suggest that Ben $109^{\top}$ and Ben 110 are sufficiently different from $\mathrm{T1}^{\mathrm{X} \mathbf{X}^{\top}}$ to represent a different species of the genus Tetrasphaera. Strain $\mathrm{T1}$ - $\mathrm{X7}^{\mathrm{T}}$ represents the type species Tetrasphaera japonica sp. nov. of this new genus, and strains Ben ${ }^{109}$ and Ben 110 belong to the other species, Tetrasphaera australiensis sp. nov.

Keywords: Tetrasphaera, activated sludge, G-bacteria, Intrasporangiaceae, biological nutrient removal

\section{INTRODUCTION}

The activated sludge process uses a deliberately

† Present address: Centre for Integrated Environmental Protection, Griffith University, Nathan, Brisbane, Queensland 4111, Australia.

The GenBank accession numbers for the 16S rRNA gene sequences of Ben $109^{\top}$, Ben 110 and $\mathrm{T} 1-\mathrm{X} 7^{\top}$ are AF125091, AF125090 and AF125092, respectively. engineered community of bacteria, protozoa and other organisms to treat domestic and industrial wastes (Seviour \& Blackall, 1999; Kämpfer, 1997; Amann et al., 1995), but our understanding of the microbes present and their roles in this process is poor (Seviour \& Blackall, 1999; Kämpfer, 1997; Bond et al., 1995; Amann et al., 1995). It is now clear that the application of molecular techniques and culture-in- 
dependent methods (Muyzer \& Smalla, 1998; Amann et al., 1998; Head et al., 1998) to the study of the microbiology of activated sludge has revealed that the diversity of microbes is much greater than once recognized using culture-dependent methods and many previously undescribed bacteria are now known to be present, often in large numbers (Seviour \& Blackall, 1999; Maszenan et al., 1997, 1999a, b; Amann et al., 1995).

The limitations of relying on cell morphology and arrangement, i.e. the conventional approach to identifying the populations present are obvious in the case of the so-called 'G-bacteria'. These bacteria were first described by Cech \& Hartman $(1990,1993)$ as Gramnegative cocci occurring in clumps and packages of tetrads. A polyphasic taxonomic approach with pure cultures of strains of these Gram-negative G-bacteria from several countries has shown that these bacteria are members of the $\alpha$-Proteobacteria and represent several species of a single novel genus Amaricoccus (Maszenan et al., 1997). However, several quite different Gram-positive cocci have also been isolated from activated sludge plants. These include members of the genera Micrococcus (Painter, 1983; Wanner, 1994), Microsphaera (Yoshimi et al., 1996) and Microlunatus (Nakamura et al., 1995). The latter two organisms have the ability to accumulate large amounts of phosphate, but have not been reported elsewhere apart from Japan. Other populations of cocci with a similar morphology, i.e. cells in clusters or tetrads, are also found in activated sludge and are shown on culture to belong to the high- $\mathrm{G}+\mathrm{C}$ group of Gram-positive bacteria. Thus Maszenan et al. (1999b) described two organisms which were novel species of Friedmanniella (Schumann et al., 1997), Friedmanniella spumicola and Friedmanniella capsulata, having previously isolated a coccus in tetrad arrangement which belongs to a new genus, Tessaracoccus (Maszenan et al., 1999a).

Many other cocci, often with the cell arrangement distinctive of the G-bacteria, have been seen in activated sludge samples (Liu et al., 1996, 1997; Carucci et al., 1995; Randall, 1994; Nielsen et al., 1999). Unfortunately, their true identities were not always confirmed as they were not cultured and characterized. Until their taxonomic status and physiology is resolved in pure culture, interpretation of their function in activated sludge systems will remain unclear.

Phylogenetic diversity among the Gram-positive cocci is well documented and it is clear that they represent a phylogenetically incoherent group of bacteria (Siefert $\&$ Fox, 1998). Such diversity will probably be reflected in physiological differences. Thus the presence of Gram-positive cocci in activated sludge samples may not always have the same significance and their functions within plants and impact on plant performance may be different. This view is supported by the observations of Liu et al. (1996) and Nakamura et al. (1995). Therefore, as part of our ongoing research to study these cocci, we have isolated further Grampositive strains of the morphotype of the so-called Gbacteria and characterized them using a polyphasic approach. This paper reveals that they form a coherent phylogenetic group based on 16S rDNA analysis and phenotypic data. We propose that all three be placed in a novel genus Tetrasphaera gen. nov. However, differences in their chemotaxonomic properties and low DNA-DNA homology would suggest that they represent two different species of this novel genus. Therefore, we propose that Ben $109^{\mathrm{T}}$ and Ben 110 are given the name Tetrasphaera australiensis sp. nov. and strain $\mathrm{T} 1-\mathrm{X} 7^{\mathrm{T}}$ is named Tetrasphaera japonica sp. nov.

\section{METHODS}

Strain isolation and maintenance. Strains Ben $109^{\mathrm{T}}$ and Ben 110 were isolated from activated sludge biomass from plants in Glenelg, South Australia, and the Eastern Treatment Plant, Melbourne, Victoria, Australia, respectively, by micromanipulation (Skerman, 1968) onto GS agar plates, as described by Maszenan et al. (1997). Plates were inspected microscopically to check for contamination and when colonies had developed (after 2-3 weeks), both isolates were streaked onto fresh GS plates. Purity of micromanipulated cells was confirmed microscopically and the pure cultures were stored at $-80{ }^{\circ} \mathrm{C}$ in GS medium plus $20 \%$ glycerol. Strain $\mathrm{T} 1-\mathrm{X} 7^{\mathrm{T}}$ was the isolate described by Kataoka et al. (1996). It was grown on modified cell extract agar which incorporated $0.25 \%$ Casamino acids instead of the cell extract from activated sludge described in the original paper (Kataoka et al., 1996). Strain T1-X $7^{\mathrm{T}}$ was stored in cell extract medium with $20 \%$ glycerol at $-80{ }^{\circ} \mathrm{C}$

Culture conditions. The biomass for phylogenetic studies was obtained by growing strains Ben $109^{\mathrm{T}}$ and Ben 110 aerobically on GS agar plates for 3-4 weeks at $25^{\circ} \mathrm{C}$. Cells from strain $\mathrm{T} 1-\mathrm{X} 7^{\mathrm{T}}$ were harvested by culturing on modified cell extract agar. The biomass for chemotaxonomic analyses was obtained by growing cultures on R2A-agar (Difco) at $25^{\circ} \mathrm{C}$ for 3-4 weeks. DNA for $\mathrm{G}+\mathrm{C}$ determination and DNA-DNA hybridization was isolated from cells grown in liquid R-medium (Yamada \& Komagata, 1972) at $28^{\circ} \mathrm{C}$ for 2-3 weeks.

Microscopic studies. Gram and polyphosphate stains were performed according to the modified Hucker method (Hucker, 1921) and the protocol of Rees et al. (1992), respectively. Gram stain results were confirmed with an alternative method employing $3 \% \mathrm{KOH}$ (Buck, 1982). Specimens for SEM were prepared as previously described by Maszenan et al. (1997).

Chemotaxonomic characterization. Diaminopimelic acid isomers in hydrolysates of bacterial cells (Hasegawa et al., 1983) were determined by descending paper chromatography according to Schleifer \& Kandler (1972). Cellular fatty acid methyl esters obtained by the method of Stead et al. (1992) were separated by GC using a non-polar (type OV1) capillary column $(25 \mathrm{~m}$ by $0.25 \mathrm{~mm}$ i.d.). Lipid components were analysed as described by Schumann et al. (1997). Menaquinones were analysed by reversed phase HPLC (Groth et al., 1996). Polar lipids were resolved by two-dimensional TLC on silica gel and identified by spraying 
with specific reagents (Collins \& Jones, 1980). Absence of mycolic acids was demonstrated by TLC (Minnikin et al., 1975).

Biochemical and physiological characterization. Enzymic profiles and biochemical characteristics of Ben $109^{\mathrm{T}}$, Ben 110 and $\mathrm{T} 1-\mathrm{X} 7^{\mathrm{T}}$ were determined using the API ZYM (BioMérieux) and Microbact 24E systems (Oxoid) as described previously (Maszenan et al., 1997). A screening of carbon substrates utilized was performed with the BIOLOG GP and GN (Special Diagnostics) microplate systems. Oxidase and catalase activities were determined using standard methods (Smibert \& Krieg, 1994). Storage polymer granule detection was by microscopic examination of cells stained for polyphosphate (PolyP) and polyhydroxyalkanoate (PHA) (Rees et al., 1992) which were grown in GS medium incorporating glucose, acetate or propionate at an initial concentration of $0.15 \mathrm{~g} \mathrm{l}^{-1}$. Temperature and $\mathrm{pH}$ ranges for growth, urease activity, nitrate reduction and motility were all determined as reported previously (Maszenan et al., 1997).

$16 \mathrm{~S}$ rDNA sequences and phylogenetic analysis. $16 \mathrm{~S}$ rDNAs of Ben $109^{\mathrm{T}}$, Ben 110 and $\mathrm{T} 1-\mathrm{X} 7^{\mathrm{T}}$ were amplified and sequenced as described by Maszenan et al. (1997) and Andrews \& Patel (1996). The new sequence data that were generated were aligned, an almost full length consensus $16 \mathrm{~S}$ rRNA gene sequence assembled and checked for accuracy manually using the alignment editor ae2 (Maidak et al., 1997). These were compared with other sequences in the GenBank database (Benson et al., 1993) using BLAST (Altschul et al., 1997), and in the Ribosomal Database Project, version 7.0 using SIMILARITY_RANK and SUGGEST TREE (Maidak et al., 1997). If necessary, reference sequences most related to our newly generated sequence were extracted from these databases and aligned. Positions of sequence and alignment uncertainty were omitted from the analysis. Pairwise evolutionary distances based on 1450 unambiguous nucleotides were computed using DNADIST (Jukes \& Cantor, 1969) and neighbour-joining programs that form part of the PHYLIP suite of programs (Felsenstein, 1993). TREECON was used extensively for bootstrap analysis and for transversion analysis (Van de Peer \& De Wachter, 1993).

DNA base composition. DNA was isolated using a modification of the Marmur method (Groth et al., 1996) and was purified with Proteinase $\mathrm{K}$ treatment. The DNA was degraded to nucleosides using P1 nuclease and bovine intestinal mucosa alkaline phosphatase according to Mesbah et al. (1989) and the nucleosides were separated by reversephase HPLC (Groth et al., 1996). The G + C content of the DNA was calculated from the ratio of deoxyguanosine to deoxythymidine.

DNA-DNA hybridization. DNA-DNA hybridization studies were carried out according to the method of De Ley et al. (1970) with the modification described by Huss et al. (1983), using a Gilford System model 2600 spectrophotometer equipped with a Gilford model 2527-R thermoprogrammer and plotter. Renaturation rates were computed with the TRANSFER.BAS program (Jahnke, 1992). DNA from Terracoccus luteus (DSM 44267 $)$, Terrabacter tumescens (DSM $20308^{\mathrm{T}}$ ), Intrasporangium calvum (DSM 43043 ${ }^{\mathrm{T}}$ ) and Janibacter limosus (DSM 11140 $)$ were included in this study as they were the closest phylogenetic relatives as shown in Fig. 2.

\section{RESULTS}

\section{Strain characteristics}

A wide range of media, which included many media successfully used in the past to cultivate activated sludge bacteria, were tried in attempts to isolate the organisms from activated sludge (Seviour \& Blackall, 1999). Only the GS medium of Williams \& Unz (1985) was successful in supporting the growth of Ben $109^{\mathrm{T}}$ and Ben 110 after micromanipulation (Skerman, 1968). However, once in pure culture, these isolates would grow on a limited number of other media (see below). The isolates obtained fit the distinctive description of G-bacteria, i.e. cocci in pairs or arranged as tetrads or in clusters of tetrads (Fig. 1). These organisms are very slow-growing, a property shared by strain $\mathrm{T} 1-\mathrm{X} 7^{\mathrm{T}}$, which was isolated from activated sludge biomass after prolonged exposure to nutrient starvation conditions (Kataoka et al., 1996). All three took up to 3 or 4 weeks for colonies to appear on agar plates and for any turbidity to occur in liquid medium. These organisms are probably aerobic as no growth occurred down the line of inoculation in stab culture.

The growth temperature range for Ben $109^{\mathrm{T}}$ grown on GS agar was between 15 and $37^{\circ} \mathrm{C}$, while both $\mathrm{T} 1-\mathrm{X} 7^{\mathrm{T}}$ and Ben 110 grew at temperatures between 20 and $37^{\circ} \mathrm{C}$. The $\mathrm{pH}$ range for growth of Ben $109^{\mathrm{T}}$, Ben 110 and $\mathrm{T} 1-\mathrm{X} 7^{\mathrm{T}}$ was between 6.0 and 8.0 in all cases and no growth occurred at $\mathrm{pH} 5.5$ or below or at $\mathrm{pH} 8.5$ and above (Table 1).

\section{Morphological characteristics}

All three organisms grew as irregular cocci in clusters of tetrads (Fig. 1c) and also sometimes as cocci in pairs (Fig. 1b). All three are Gram-positive cocci with the modified Gram staining of Hucker (1921) which was confirmed by the absence of cell stringiness with $3 \%$ $\mathrm{KOH}$ treatment (Buck, 1982). Flagella were never observed in any of the three isolates, showing that they are non-motile, and endospores were never observed. PolyP granules were observed in all three isolates when grown aerobically in medium incorporating glucose, acetate or propionate as sole carbon source. However no polyhydroxyalkanoate (PHA) granules were detected. The mean cell diameters of individual coccal cells were $0 \cdot 5-1 \cdot 0 \mu \mathrm{m}$ for Ben $109^{\mathrm{T}}$, $0 \cdot 4-1 \cdot 1 \mu \mathrm{m}$ for Ben 110 and $0 \cdot 6-1 \cdot 4 \mu \mathrm{m}$ for $\mathrm{T} 1-\mathrm{X} 7^{\mathrm{T}}$ grown on GS agar and modified cell extract agar, respectively.

\section{Chemotaxonomic characteristics}

All three isolates are characterized by type $\mathrm{A} 1 \gamma$ peptidoglycan with meso-diaminopimelic acid ( $m$ $\mathrm{A}_{2} \mathrm{pm}$ ) as the diagnostic diamino acid (Schleifer \& Kandler, 1972). The cellular fatty acid profiles of the 

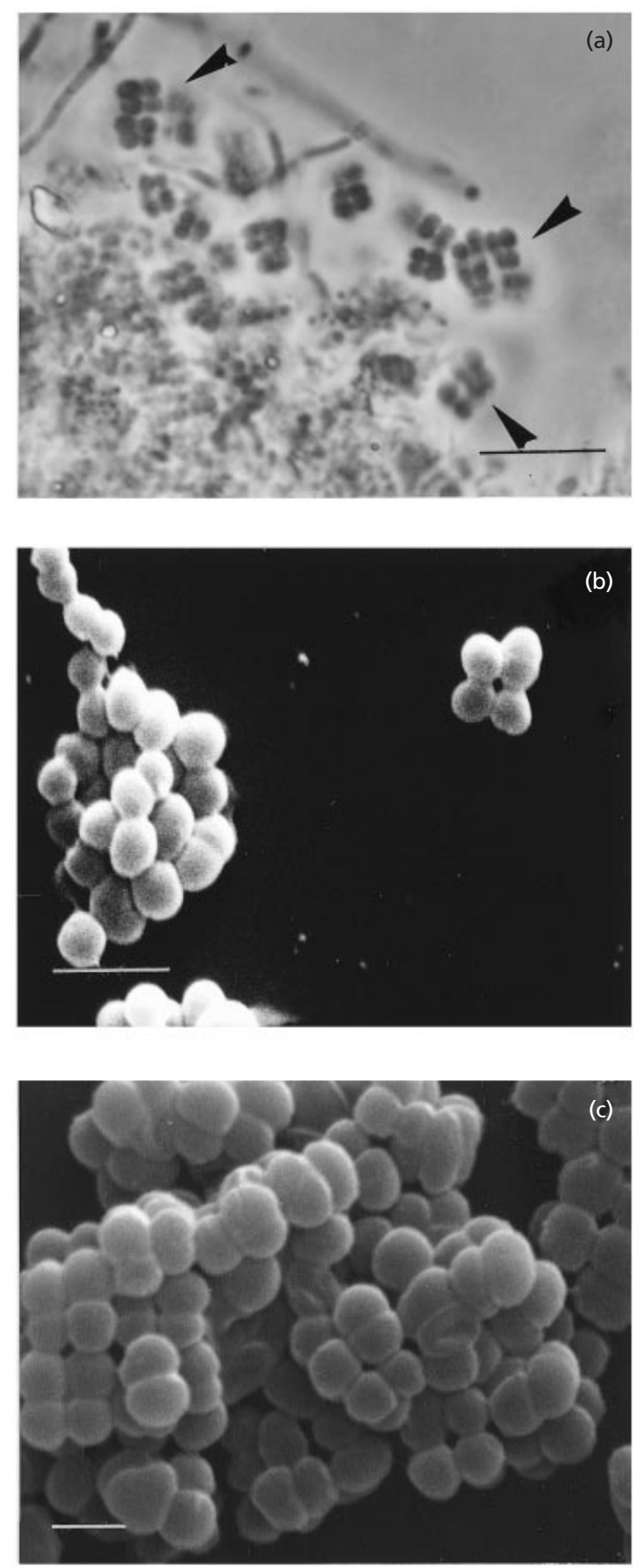

Fig. 1. (a) Tetrads of Gram-positive G-bacteria (arrows) in a mixed liquor sample from the Glenelg Plant, South Australia. Bar, $10 \mu \mathrm{m}$. (b) Scanning electron micrograph of a pure culture of Ben 110 from the Eastern Treatment Plant, Melbourne, Australia, showing a tetrad and aggregates of coccoid cells. Bar, $2 \mu \mathrm{m}$. (c) Scanning electron micrograph of an axenic culture of Ben $109^{\top}$ from the Glenelg Plant, South Australia, showing coccoid cells in tetrads organized into clusters. Bar, $1 \mu \mathrm{m}$. three strains were dominated by 14-methylpentadecanoic acid (i- $\left.\mathrm{C}_{16: 0}\right)$ and 14-methylhexadecanoic acid (ai- $\mathrm{C}_{17: 0}$ ) (Table 2). However, differences were observed in strain $\mathrm{T} 1-\mathrm{X} 7^{\mathrm{T}}$ which contained $\mathrm{i}-2 \mathrm{OH}-$ $\mathrm{C}_{16: 0}, 2 \mathrm{OH}-\mathrm{C}_{17: 0}, \mathrm{i}-\mathrm{C}_{18: 0}, \mathrm{i}-\mathrm{C}_{18: 1}$ and tuberculostearic acid (TBSA) which were not found in strains Ben $109^{\mathrm{T}}$ or Ben 110. Strains Ben $109^{\mathrm{T}}$ and Ben 110 contained 12-methyltridecanoic acid $\left(\mathrm{i}-\mathrm{C}_{14: 0}\right)$ and hexadecanoic acid $\left(\mathrm{C}_{16: 0}\right)$ which were not present in $\mathrm{T} 1-\mathrm{X} 7^{\mathrm{T}}$. These similarities and differences in cellular fatty acid composition in the three strain are summarized in Table 2. Three isoprenoid quinones, $\mathrm{MK}-8\left(\mathrm{H}_{4}\right), \mathrm{MK}-6\left(\mathrm{H}_{4}\right)$ and MK-8 $\left(\mathrm{H}_{2}\right)$ with a composition ratio of $57: 30: 2$ were observed in Ben 110, while Ben $109^{\mathrm{T}}$ possessed MK$8\left(\mathrm{H}_{4}\right)$, MK- $8\left(\mathrm{H}_{2}\right)$ and $\mathrm{MK}-8$ in the ratio of $77: 6: 5$. T1$\mathrm{X} 7^{\mathrm{T}}$ contained, in addition to $\mathrm{MK}-8\left(\mathrm{H}_{4}\right)$, the menaquinones MK-7 $\left(\mathrm{H}_{4}\right)$ and $\mathrm{MK}-6\left(\mathrm{H}_{4}\right)$ in the ratio of $88: 2: 2$ (Table 1). All three isolates possessed diphosphatidylglycerol, phosphatidylglycerol and phosphatidylinositol as polar lipids. However, both Ben $109^{\mathrm{T}}$ and $\mathrm{T} 1-\mathrm{X} 7^{\mathrm{T}}$ had an additional unknown phospholipid, while $\mathrm{T} 1-\mathrm{X} 7^{\mathrm{T}}$ contained an unknown amino phospholipid and Ben 110 had phosphatidylethanolamine (Table 1). None of the three strains contained mycolic acids.

\section{Physiological and biochemical characteristics}

All three organisms showed a very limited ability to utilize substrates as determined using the BIOLOG GN and GP systems even after 4 weeks incubation, probably reflecting their slow growth rate and low level of metabolic activity. Alternatively, the BIOLOG systems may be unsuitable for screening these organisms. Differences in substrate utilization patterns for Ben $109^{\mathrm{T}}$, Ben 110 and $\mathrm{T} 1-\mathrm{X} 7^{\mathrm{T}}$ are summarized in Table 3. Enzymes detected in all three strains were alkaline phosphatase, esterase, esterase lipase, lipase, leucine arylamidase, valine arylamidase, cystine arylamidase, acid phosphatase, naphthol-AS-BI-phosphohydrolase, $\alpha$-galactosidase, $\beta$-galactosidase, $\alpha$-glucosidase and $\beta$-glucosidase. None of these isolates produced $\mathrm{H}_{2} \mathrm{~S}$ or reduced nitrate and did not hydrolyse gelatin or produce urease.

\section{DNA base composition and DNA-DNA similarity data}

DNA-DNA similarity data show that Ben 110 is related to T1-X7 ${ }^{\mathrm{T}}$, Terracoccus luteus (Prauser et al., 1997), Terrabacter tumescens (Collins et al., 1989), Janibacter limosus (Martin et al., 1997) and Intrasporangium calvum (Kalakoutskii et al., 1967) with 50, $55,41,45$ and $55 \%$ DNA homology, respectively (Table 4). The DNA base compositions of Ben $109^{\mathrm{T}}$, Ben 110 and $\mathrm{T} 1-\mathrm{X} 7^{\mathrm{T}}$ are 70,68 and $71 \mathrm{~mol} \%$ (Table $1)$, respectively.

\section{Phylogenetic analysis}

An almost complete sequence of the 16S rRNA gene for strains Ben $109^{\mathrm{T}}$ (1470 nt), Ben 110 (1477 nt), T1$\mathrm{X} 7^{\mathrm{T}}(1445 \mathrm{nt})$ corresponding to positions 21-1513, 
Table 1. Comparative phenotypic properties of the genera Janibacter, Terrabacter, Terracoccus, Intrasporangium, Sanguibacter and strains Ben $109^{\top}$, Ben 110 and $\mathrm{T} 1-\mathrm{X}^{\top}$

+ , Positive result; -, negative result; ND, not determined. An arrow indicates a growth cycle, i.e. cocci to rods in Janibacter, rods to cocci in Terrabacter. DPG, diphosphatidylglycerol; PG, phosphatidylglycerol; PI, phosphatidylinositol; PE, phosphatidylethanolamine, PL, unknown phospholipid(s); PIM, phosphatidyl inositol mannosides; APL, unknown amino phospholipid.

\begin{tabular}{|c|c|c|c|c|c|c|c|c|}
\hline $\begin{array}{l}\text { Phenotypic } \\
\text { property }\end{array}$ & Ben $109^{\mathrm{T}}$ & Ben 110 & $\mathrm{~T} 1-\mathrm{X} 7^{\mathrm{T}}$ & Janibacter* & Terrabacter $\dagger$ & Terracoccus & Intrasporangium $\S$ & Sanguibacter $\|$ \\
\hline $\mathrm{O}_{2}$ requirement & Aerobic & Aerobic & Aerobic & Aerobic & Obligately aerobic & Strictly aerobic & Aerobic & $\begin{array}{c}\text { Facultatively } \\
\text { anaerobic }\end{array}$ \\
\hline Cell morphology & $\begin{array}{l}\text { Cocci, single, in } \\
\text { pairs, in tetrad } \\
\text { arrangement and } \\
\text { clusters } \\
(0.5-1.0 \mu \mathrm{m})\end{array}$ & $\begin{array}{l}\text { Cocci, single, in } \\
\text { pairs, in tetrad } \\
\text { arrangement and } \\
\text { clusters } \\
(0 \cdot 4-1 \cdot 1 \mu \mathrm{m})\end{array}$ & $\begin{array}{l}\text { Cocci, single, in } \\
\text { pairs, in tetrad } \\
\text { arrangement and } \\
\text { clusters } \\
(0 \cdot 6-1 \cdot 4 \mu \mathrm{m})\end{array}$ & $\begin{array}{l}\text { Cocci } \rightarrow \text { rods, } \\
\text { single, in pairs } \\
\text { and also in } \\
\text { irregular clumps } \\
(0 \cdot 3-1 \cdot 2 \mu \mathrm{m})\end{array}$ & $\begin{array}{l}\text { Rods } \leftarrow \text { cocci } \\
(0 \cdot 6-1 \cdot 0 \\
\times 2 \cdot 0-7 \cdot 0 \mu \mathrm{m})\end{array}$ & $\begin{array}{l}\text { Cocci, in pairs, } \\
\text { tetrads and small } \\
\text { clusters } \\
(0 \cdot 7-1 \cdot 3 \mu \mathrm{m})\end{array}$ & Sporangia & $\begin{array}{l}\text { Short irregular } \\
\text { rods }\end{array}$ \\
\hline Habitat & $\begin{array}{l}\text { Sewage treatment } \\
\text { plant in South } \\
\text { Australia }\end{array}$ & $\begin{array}{l}\text { Sewage treatment } \\
\text { plant in } \\
\text { Melbourne, } \\
\text { Victoria, } \\
\text { Australia }\end{array}$ & $\begin{array}{l}\text { Activated sludge } \\
\text { biomass in Japan }\end{array}$ & $\begin{array}{l}\text { Sludge, sewage } \\
\text { waste }\end{array}$ & Soil & $\begin{array}{l}\text { Soil and at } \\
\text { water/soil } \\
\text { interface of duck } \\
\text { pond }\end{array}$ & $\begin{array}{l}\text { From air in school } \\
\text { dining room }\end{array}$ & $\begin{array}{l}\text { Blood and milk of } \\
\text { healthy cows }\end{array}$ \\
\hline $\begin{array}{l}\text { Optimum growth } \\
\text { temperature }\left({ }^{\circ} \mathrm{C}\right)\end{array}$ & 25 & 25 & 25 & 28 & $25-30$ & 28 & 37 & $25-30$ \\
\hline $\begin{array}{l}\text { Growth } \\
\text { temperature } \\
\text { range }\left({ }^{\circ} \mathrm{C}\right)\end{array}$ & $15-37$ & $20-37$ & $20-37$ & $28-37$ & $10-35$ & $15-37$ & $28-37$ & $25-30$ \\
\hline $\begin{array}{l}\text { Optimum growth } \\
\mathrm{pH}\end{array}$ & $7 \cdot 0$ & $7 \cdot 0-7 \cdot 5$ & $7 \cdot 0$ & ND & $\mathrm{ND}$ & $6 \cdot 0-7 \cdot 2$ & $\mathrm{ND}$ & $\mathrm{ND}$ \\
\hline Growth $\mathrm{pH}$ range & $6 \cdot 0-8 \cdot 0$ & $6 \cdot 0-8 \cdot 0$ & $6 \cdot 0-8 \cdot 0$ & ND & ND & $4 \cdot 5-9 \cdot 5$ & ND & ND \\
\hline Catalase & + & + & \pm & + & + & + & ND & + \\
\hline Oxidase & + & - & + & - & - & - & ND & - \\
\hline Nitrate reduction & - & - & - & + & + & - & + & + \\
\hline Urease & - & - & - & - & - & + & ND & - \\
\hline $\begin{array}{l}\mathrm{G}+\mathrm{C} \text { content } \\
(\mathrm{mol} \%)\end{array}$ & 70 & 68 & 71 & 70 & $70-73$ & 73 & 68 & $69-70$ \\
\hline Production of $\mathrm{H}_{2} \mathrm{~S}$ & - & - & - & + & ND & + & ND & ND \\
\hline $\begin{array}{l}\text { Production of } \\
\text { indole }\end{array}$ & - & - & - & + & $\mathrm{ND}$ & ND & $\mathrm{ND}$ & ND \\
\hline Motility & Non-motile & Non-motile & Non-motile & Non-motile & $\begin{array}{l}\text { Rods are non- } \\
\text { motile, } \\
\text { occasionally } \\
\text { motile }\end{array}$ & Non-motile & Non-motile & Non-motile \\
\hline $\begin{array}{l}\text { Major } \\
\text { menaquinone }\end{array}$ & MK- $8\left(\mathrm{H}_{4}\right)$ & $\begin{array}{l}\left.\text { MK-8( } \mathrm{H}_{4}\right), \text { MK- } \\
6\left(\mathrm{H}_{4}\right)\end{array}$ & MK- $8\left(\mathrm{H}_{4}\right)$ & MK- $8\left(\mathrm{H}_{4}\right)$ & MK-8(II, III-H $\left.{ }_{4}\right)$ & MK- $8\left(\mathrm{H}_{4}\right)$ & MK-8 & MK-9 $\left(\mathrm{H}_{4}\right)$ \\
\hline Spore formation & $\begin{array}{l}\text { No spore } \\
\text { formation }\end{array}$ & $\begin{array}{l}\text { No spore } \\
\text { formation }\end{array}$ & $\begin{array}{l}\text { No spore } \\
\text { formation }\end{array}$ & $\begin{array}{l}\text { No spore } \\
\text { formation }\end{array}$ & $\begin{array}{l}\text { No spore } \\
\text { formation }\end{array}$ & $\begin{array}{l}\text { No spore } \\
\text { formation }\end{array}$ & Spore formation & $\mathrm{ND}$ \\
\hline $\begin{array}{l}\text { Diamino } \\
\text { acid/murein type }\end{array}$ & $m-\mathrm{A}_{2} \mathrm{pm}(\mathrm{A} 1 \gamma)$ & $m-\mathrm{A}_{2} \mathrm{pm}(\mathrm{A} 1 \gamma)$ & $m-\mathrm{A}_{2} \mathrm{pm}(\mathrm{Al} \gamma)$ & $m-\mathrm{A}_{2} \mathrm{pm}(\mathrm{A} 1 \gamma)$ & LL-A ${ }_{2} \mathrm{pm}(\mathrm{A} 3 \gamma)$ & LL-A ${ }_{2} \mathrm{pm}(\mathrm{A} 3 \gamma)$ & LL-A ${ }_{2} \mathrm{pm}(\mathrm{A} 3 \gamma)$ & L-Lysine (A $4 \alpha)$ \\
\hline Gelatin hydrolysis & - & - & - & + & + & + & - & + \\
\hline Polar lipids & DPG, PG, PI, PL & DPG, PG, PI, PE & $\begin{array}{l}\text { DPG, PG, PI, PL, } \\
\text { APL }\end{array}$ & DPG, PG, PI & DPG, PI, PE, PL & DPG, PG, PI, PE & $\begin{array}{l}\text { DPG, PG, PI, } \\
\text { PIM }\end{array}$ & ND \\
\hline
\end{tabular}

* Data from Martin et al. (1997).

$\dagger$ Data from Collins et al. (1989).

$\$$ Data from Prauser et al. (1997).

$\S$ Data from Kalakoutskii et al. (1967) and Kalakoutskii (1989).

|| Data from Fernández-Garayzábal et al. (1995) and Pascual et al. (1996).

13-1512 and 15-1478 of the Escherichia coli sequence according to the nomenclature of Winker \& Woese (1991), respectively, was obtained. Phylogeny after 16S rDNA analysis indicates all three isolates belong to the high-G $+\mathrm{C}$ group of the Gram-positive bacteria in the domain Bacteria. The phylogenetic tree shows that Ben $109^{\mathrm{T}}$, Ben 110 and $\mathrm{T} 1-\mathrm{X} 7^{\mathrm{T}}$ form a cluster at a level of $97.0 \%$ similarity, with Terrabacter, Terracoccus, Sanguibacter (Fernández-Garayzábal et al., 1995; Pascual et al., 1996), Intrasporangium and Janibacter as their closest relatives (Fig. 2). Transversion analysis did not change the relative positions of the newly isolated strains in the phylogenetic tree. These organisms are currently classified in the Intrasporangiaceae family in the suborder Micrococcineae (Stackebrandt et al., 1997), even though the genera Terracoccus and Janibacter were not included in the proposed scheme of Stackebrandt et al. (1997). 
Table 2. Percentage cellular fatty acid composition of Ben $109^{\top}$, Ben $110, \mathrm{~T} 1-\mathrm{X} 7^{\top}$, Terracoccus luteus, Terrabacter tumescens, Janibacter limosus, Sanguibacter and Intrasporangium calvum

Values less than $1 \%$ are not shown. Abbreviations for fatty acids are as follows: $\mathrm{C}_{16: 0}$, hexadecanoic acid; $\mathrm{C}_{18: 1}$, octadecenoic acid; $\mathrm{i}_{\text {- }} \mathrm{C}_{15: 0}, 13$-methyltetradecanoic acid; ai- $\mathrm{C}_{15: 0}, 12$-methyltetradecanoic acid; TBSA, tuberculostearic acid. $\mathrm{i}$, iso; ai, anteiso.

\begin{tabular}{|c|c|c|c|c|c|c|c|c|c|c|c|}
\hline Fatty acid & Ben $109^{\mathrm{T}}$ & Ben 110 & $\mathrm{~T} 1-\mathrm{X} 7^{\mathrm{T}}$ & $\begin{array}{c}\text { Terracoccus } \\
\text { luteus* }\end{array}$ & $\begin{array}{c}\text { Terrabacter } \\
\text { tumescens } \dagger\end{array}$ & $\begin{array}{c}\text { Janibacter } \\
\text { limosus }\end{array}$ & $\begin{array}{c}\text { Sanguibacter } \\
\text { ST-26\$ }\end{array}$ & $\begin{array}{c}\text { Sanguibacter } \\
\text { ST-86\$ }\end{array}$ & $\begin{array}{l}\text { Sanguibacter } \\
\text { ST-74\$ }\end{array}$ & $\begin{array}{c}\text { Sanguibacter } \\
\text { ST-167§ }\end{array}$ & $\begin{array}{l}\text { Intrasporangium } \\
\quad \text { calvum } \|\end{array}$ \\
\hline $\mathrm{i}-\mathrm{C}_{13: 0}$ & - & - & - & $1 \cdot 1$ & - & - & - & - & - & - & - \\
\hline ai-C $_{13: 0}$ & - & - & - & $1 \cdot 1$ & - & - & $0 \cdot 8$ & - & - & - & - \\
\hline $\mathrm{i}-\mathrm{C}_{14: 0}$ & $2 \cdot 6$ & 1.5 & - & $3 \cdot 5$ & $24 \cdot 2$ & $0 \cdot 5$ & 1.5 & - & $1 \cdot 1$ & $0 \cdot 9$ & $5 \cdot 0$ \\
\hline $\mathrm{C}_{14: 0}$ & - & - & - & $1 \cdot 8$ & - & $0 \cdot 4$ & $14 \cdot 8$ & $13 \cdot 1$ & $5 \cdot 8$ & $4 \cdot 1$ & - \\
\hline $\mathrm{i}-\mathrm{C}_{15: 0}$ & $12 \cdot 1$ & $9 \cdot 3$ & $6 \cdot 4$ & $34 \cdot 3$ & $35 \cdot 4$ & $1 \cdot 7$ & $3 \cdot 6$ & $3 \cdot 7$ & $3 \cdot 2$ & $4 \cdot 4$ & $37 \cdot 8$ \\
\hline $\mathrm{i}-\mathrm{C}_{15: 1}$ & - & - & - & - & 1.5 & - & - & - & - & - & $3 \cdot 5$ \\
\hline ai- $C_{15: 0}$ & $7 \cdot 6$ & $1 \cdot 4$ & $3 \cdot 0$ & $30 \cdot 4$ & $3 \cdot 7$ & $0 \cdot 3$ & 38.9 & $42 \cdot 1$ & $11 \cdot 4$ & $22 \cdot 7$ & $12 \cdot 6$ \\
\hline ai- $C_{15: 1}^{15: 0}$ & - & - & - & - & - & - & 1.0 & 1.8 & $1 \cdot 6$ & $1 \cdot 3$ & \\
\hline$C_{15: 0}$ & $4 \cdot 0$ & $1 \cdot 3$ & $1 \cdot 1$ & 1.9 & $1 \cdot 1$ & $3 \cdot 8$ & $1 \cdot 1$ & - & $0 \cdot 5$ & - & $2 \cdot 7$ \\
\hline $\mathrm{C}_{15: 1}$ & - & $1 \cdot 2$ & - & $0 \cdot 1$ & - & $0 \cdot 3$ & - & - & - & - & 1.5 \\
\hline $\mathrm{i}-\mathrm{C}_{16: 0}$ & $27 \cdot 1$ & $34 \cdot 8$ & $25 \cdot 8$ & $2 \cdot 5$ & $13 \cdot 4$ & $17 \cdot 5$ & $2 \cdot 7$ & $2 \cdot 5$ & $5 \cdot 4$ & $3 \cdot 4$ & $12 \cdot 3$ \\
\hline $\mathrm{i}-\mathrm{C}_{16: 1}$ & $9 \cdot 7$ & $12 \cdot 4$ & $3 \cdot 2$ & - & $8 \cdot 6$ & 0 & - & - & - & - & $3 \cdot 1$ \\
\hline$C_{16: 0}^{16: 1}$ & $5 \cdot 9$ & 1.7 & - & $10 \cdot 0$ & - & $3 \cdot 9$ & $33 \cdot 7$ & $34 \cdot 8$ & $53 \cdot 3$ & $34 \cdot 5$ & $1 \cdot 2$ \\
\hline $\mathrm{C}_{16: 1}$ & $8 \cdot 4$ & $6 \cdot 2$ & $1 \cdot 2 \& 4 \cdot 4$ & $0 \cdot 9$ & $1 \cdot 4$ & $2 \cdot 4$ & - & - & - & - & - \\
\hline $\mathrm{i}-\mathrm{C}_{17: 0}$ & - & $2 \cdot 0$ & $2 \cdot 2$ & $1 \cdot 0$ & - & $1 \cdot 3$ & - & - & $1 \cdot 4$ & $2 \cdot 3$ & 1.7 \\
\hline ai-C $_{17: 0}$ & $14 \cdot 1$ & $10 \cdot 1$ & 20.5 & $4 \cdot 1$ & - & - & $1 \cdot 2$ & $2 \cdot 0$ & $2 \cdot 4$ & $6 \cdot 3$ & $3 \cdot 9$ \\
\hline $\mathrm{i}-\mathrm{C}_{17: 1}$ & - & $2 \cdot 0$ & $2 \cdot 3$ & - & - & 0 & - & - & - & - & $3 \cdot 7$ \\
\hline $\mathrm{C}_{17: 0}$ & - & $1 \cdot 2$ & $1 \cdot 3$ & $1 \cdot 4$ & - & $20 \cdot 5$ & - & - & $0 \cdot 5$ & - & 1.0 \\
\hline$C_{17: 1}$ & - & - & - & - & $2 \cdot 4$ & $29 \cdot 7$ & - & - & - & - & - \\
\hline ai- $C_{17: 1}$ & $4 \cdot 7$ & $2 \cdot 2$ & $6 \cdot 9$ & - & - & $0 \cdot 2$ & - & - & - & - & - \\
\hline $\mathrm{i}-2 \mathrm{OH}-\mathrm{C}_{16: 0}$ & - & - & $6 \cdot 1$ & - & - & - & - & - & - & - & - \\
\hline $2 \mathrm{OH}-\mathrm{C}_{17: 0}$ & - & - & $5 \cdot 3$ & - & - & - & - & - & - & - & - \\
\hline $\mathrm{i}-\mathrm{C}_{18: 0}$ & - & - & $5 \cdot 3$ & - & - & $1 \cdot 4$ & - & - & - & - & - \\
\hline $\mathrm{i}-\mathrm{C}_{18: 1}$ & - & - & $1 \cdot 3$ & - & - & $0 \cdot 7$ & - & - & - & - & - \\
\hline $\mathrm{C}_{18: 0}$ & - & - & - & $2 \cdot 2$ & - & $2 \cdot 4$ & $0 \cdot 7$ & - & $10 \cdot 1$ & $13 \cdot 8$ & - \\
\hline$C_{18: 1}$ & $3 \cdot 7$ & $9 \cdot 7$ & $2 \cdot 2$ & $3 \cdot 6$ & - & $8 \cdot 1$ & - & - & $1 \cdot 1$ & - & - \\
\hline $\mathrm{C}_{20: 0}$ & - & - & - & - & - & - & - & - & $2 \cdot 2$ & $6 \cdot 3$ & - \\
\hline TBSA & - & - & 1.5 & - & - & - & - & - & - & - & - \\
\hline
\end{tabular}

* Data from Prauser et al. (1997).

$\dagger$ Data from Prauser et al. (1997).

\$ Data from Martin et al. (1997).

§ Data from Fernández-Garayzábal et al. (1995).

|| Data from Kalakoutskii et al. (1967); Kalakoutskii (1989), Schumann et al. (1997).

- Two isomers of $\mathrm{C}_{16: 1}$.

\section{DISCUSSION}

All three isolates described here, Ben $109^{\mathrm{T}}$, Ben 110 and $\mathrm{T} 1-\mathrm{X} 7^{\mathrm{T}}$, from activated sludge are aerobic, nonmotile, non-spore-forming, very slow-growing, Grampositive cocci, occurring singly and in pairs, but predominantly as tetrads and clusters. All can store phosphate as polyphosphate granules. Our understanding of the bacteria responsible for phosphate removal in activated sludge is poor, although some work has shown that bacteria possessing menaquinone MK-8 $\left(\mathrm{H}_{4}\right)$ are a major component of communities of such systems (Hiraishi et al., 1998). All three bacteria in this study contain MK-8 $\left(\mathrm{H}_{4}\right)$, as does Janibacter which was also isolated from activated sludge (Martin et al., 1997). Therefore, genus-specific probes for their in situ detection, together with microautoradiography (Andreasen \& Nielsen, 1997; Nielsen et al., 1998) would be useful to clarify their contribution, if any, to this process.
Table 3. Comparative substrate utilization patterns of strains Ben $109^{\top}$, Ben 110 and $\mathrm{T} 1-\mathrm{X7}^{\top}$

\begin{tabular}{|lccc|}
\hline Substrate* $^{*}$ & T1-X7 & Ben 109 $^{\mathbf{T}}$ & Ben 110 \\
\hline Tween 40 & - & + & + \\
Tween 80 & - & + & + \\
Sucrose & - & + & + \\
D-Trehalose & - & + & + \\
3-Methyl glucose & - & + & + \\
D-Xylose & - & + & + \\
Pyruvic acid & + & - & - \\
Adenosine-5'-monophosphate & - & + & + \\
Lysine & - & + & - \\
$\beta$-Galactosidase & - & + & - \\
\hline
\end{tabular}

* Determined by BIOLOG GN and GP systems, Microbact 24E and API ZYM. None of the other substrates (a total 155) gave a positive result even after several weeks of incubation. 
Table 4. Levels of DNA-DNA similarity between strains Ben $109^{\top}$, Ben $110, \mathrm{~T} 1-\mathrm{X} 7^{\top}$, Terracoccus luteus, Terrabacter tumescens, Janibacter limosus and Intrasporangium calvum

\begin{tabular}{|lccc|}
\hline \multirow{2}{*}{ Strain } & \multicolumn{3}{c|}{ Percentage relatedness to: } \\
\cline { 2 - 4 } & Ben $\mathbf{1 0 9}^{\mathrm{T}}$ & Ben $\mathbf{1 1 0}$ & $\mathbf{T 1}-\mathbf{X} 7^{\mathrm{T}}$ \\
\hline Ben 109 & & & \\
Ben 110 & 89 & & \\
T1-X7 & 41 & 50 & \\
Terracoccus luteus & $\mathrm{ND}$ & 55 & 49 \\
Terrabacter tumescens & $\mathrm{ND}$ & 41 & 47 \\
Janibacter limosus & 40 & 45 & 62 \\
Intrasporangium calvum & $\mathrm{ND}$ & 55 & 58 \\
\hline
\end{tabular}

ND, Not determined.

Phylogenetically, 16S rDNA sequence analyses reveal that Ben $109^{\mathrm{T}}$, Ben 110 and $\mathrm{T} 1-\mathrm{X} 7^{\mathrm{T}}$ form a coherent cluster at a high similarity value $(>97 \%)$ in the class Actinobacteria in the domain Bacteria. Their closest relatives are the genera Terrabacter, Terracoccus, Sanguibacter, Intrasporangium and Janibacter, all in the family Intrasporangiaceae (Fig. 2), which, as discussed below, appears now to represent a more heterogeneous group of bacteria than once thought.
All three strains have $m-\mathrm{A}_{2} \mathrm{pm}$ and type A $1 \gamma$ peptidoglycan, a feature they share with members of the genus Janibacter, but none of the other genera mentioned, which all possess LL-A 2 PM as their dibasic amino acid and type A $3 \gamma$ peptidoglycan instead (Table 1). However, cellular fatty acid profiles, together with DNA homology data and 16S rDNA sequences signature positions (Table 5) suggest that Ben $109^{\mathrm{T}}$, Ben 110 and strain $\mathrm{T} 1-\mathrm{X} 7^{\mathrm{T}}$ represent members of novel single genus, which we have called Tetrasphaera gen. nov., and should not be placed in any of the genera Terrabacter, Terracoccus, Sanguibacter, Intrasporangium or Janibacter.

Even though their 16S rDNA sequences support the view that these isolates all belong to the same genus, in our opinion these and other characters are not consistent with the idea that all three represent a single species. Thus, although a DNA-DNA homology value of $>70 \%$ shows Ben $109^{\mathrm{T}}$ and Ben 110 to be members of the same genomic species (Stackebrandt \& Goebel, 1994; Fox et al., 1992), this value between $\mathrm{T} 1-\mathrm{X} 7^{\mathrm{T}}$ and both Ben $109^{\mathrm{T}}$ and Ben 110 is $<50 \%$ (Table 4) and illustrates that the former is not as closely related to these strains as they are to each other. In addition, the presence of menaquinone MK- $8\left(\mathrm{H}_{2}\right)$ and fatty acid i$\mathrm{C}_{14: 0}$ in both Ben $109^{\mathrm{T}}$ and Ben 110 , but not in $\mathrm{T} 1-\mathrm{X} 7^{\mathrm{T}}$, which has MK-7 $\left(\mathrm{H}_{2}\right)$ and hydroxylated fatty acids, i$\mathrm{C}_{18: 0}$ and $\mathrm{i}-\mathrm{C}_{18: 1}$, and other phenotypic differences

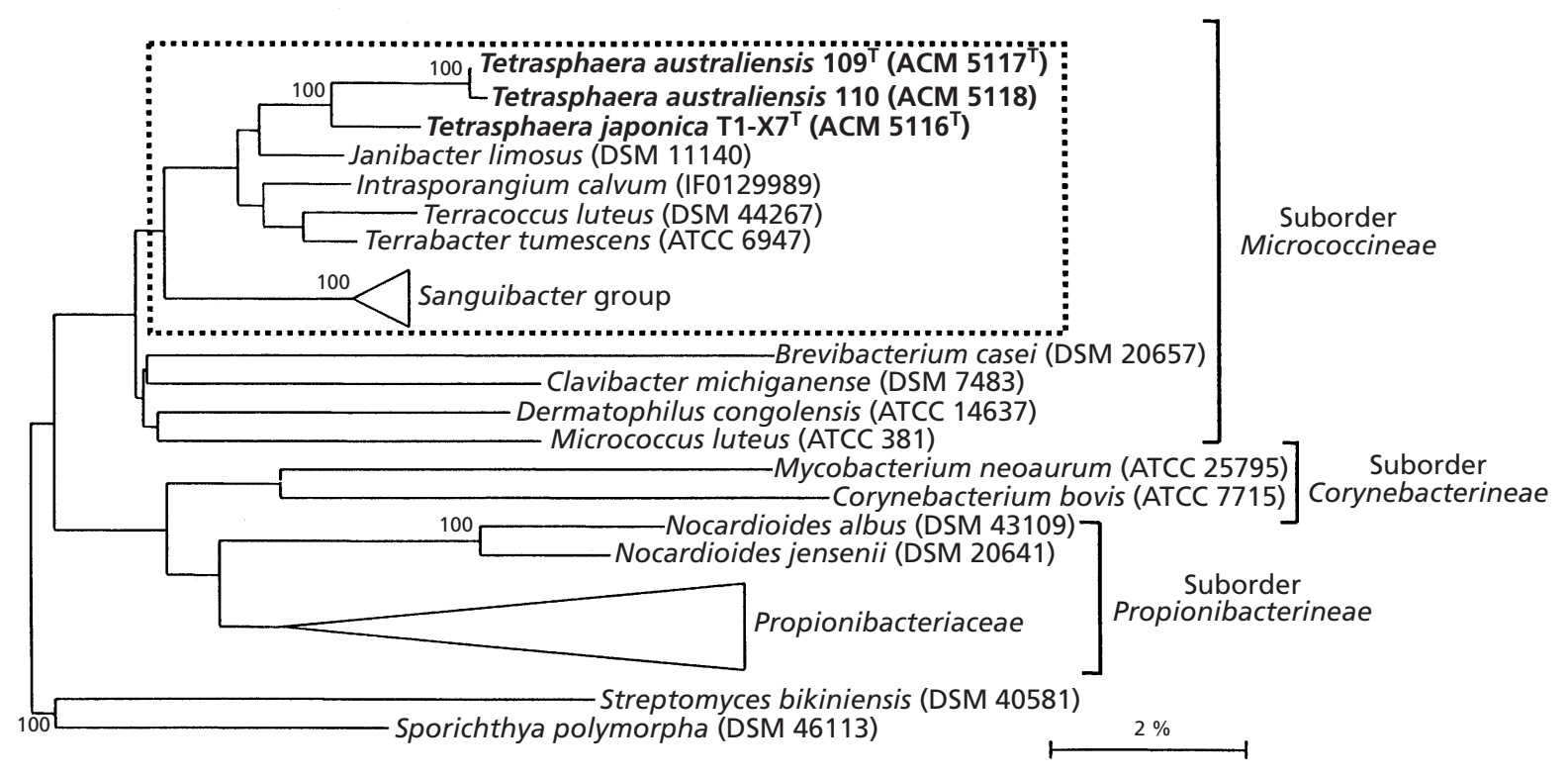

Fig. 2. Dendrogram based on $16 \mathrm{~S}$ rDNA sequence data indicating the positions of Tetrasphaera australiensis (Ben $109^{\top}$ and Ben 110) and Tetrasphaera japonica $\left(\mathrm{T} 1-\mathrm{X} \mathrm{T}^{\mathrm{T}}\right.$ ) within the family Intrasporangiaceae (shaded box), suborder Micrococcineae and their relationship to other members of the order Actinomycetales. All sequences used in the analysis were obtained from the Ribosomal Database Project, version 7.0 (Maidak et al., 1997) with the exception of Sanguibacter inulinus, Sanguibacter keddieii, Sanguibacter suarezii, Intrasporangium calvum, Janibacter limosus and Terracoccus luteus, which were extracted from GenBank (accession nos X79451, X79450, X79452, D85486, Y08539 and Y11928, respectively). Bootstrap values greater than $90 \%$ (generated from 100 data sets) are shown at the branching points. The two triangles represent clusters consisting of Sanguibacter inulinus, Sanguibacter keddieii, Sanguibacter suarezii (designated Sanguibacter group) and the genera Propionibacterium, Luteococcus, Propioniferax, Microlunatus and Tessaracoccus (designated Propionibacteriaceae). Scale bar indicates $2 \mathrm{nt}$ substitutions per $100 \mathrm{nt}$. 
Table 5. 16S rDNA nucleotide signatures for Ben $109^{\top}$, Ben 110, $\mathrm{T} 1-\mathrm{X} 7^{\top}$ and members of the family Intrasporangiaceae

\begin{tabular}{|c|c|c|c|c|c|c|c|c|c|}
\hline Position* & Intrasporangiaceae & Ben $109^{\mathrm{T}}$ & Ben 110 & $\mathrm{~T} 1-\mathrm{X} 7^{\mathrm{T}}$ & $\begin{array}{c}\text { Intrasporangium } \\
\text { calvum }\end{array}$ & Sanguibacter & Terrabacter & Janibacter & Terracoccus \\
\hline $30-553$ & C-G & C-G & C-G & C-G & C-G & C-G & C-G & C-G & C-G \\
\hline 69-99 & G-T & G-T & G-T & G-T & G-T & G-T & G-T & G-T & G-T \\
\hline $140-223$ & G-C & G-C & G-C & G-C & G-C & G-C & G-C, $\underline{\mathrm{A}-\mathrm{T}^{\dagger}}, \underline{\mathrm{G}-\mathrm{T}}+$ & $\underline{\mathrm{G}-\mathrm{T}} \S, \underline{\mathrm{A}-\mathrm{T}} \|$ & G-C \\
\hline $157-164$ & G-C & $\underline{\mathrm{T}-\mathrm{A}}$ & $\underline{\mathrm{T}-\mathrm{A}}$ & $\mathrm{G}-\mathrm{C}$ & $\mathrm{G}-\mathrm{C}$ & $\mathrm{G}-\mathrm{C}$ & $\mathrm{G}-\overline{\mathrm{C}, \mathrm{T}-\mathrm{G}} \bar{\dagger}$ & $\underline{T-G \S}$ & $\mathrm{G}-\mathrm{C}$ \\
\hline $258-268$ & A-T & $\overline{\mathrm{A}-\mathrm{T}}$ & $\overline{\mathrm{A}-\mathrm{T}}$ & A-T & A-T & A-T & A-T & $\overline{\mathrm{A}-\mathrm{T}}$ & A-T \\
\hline 630 & $\mathrm{C}$ & $\mathrm{C}$ & $\mathrm{C}$ & $\mathrm{C}$ & $\mathrm{C}$ & $\mathrm{C}$ & $\mathrm{C}$ & $\mathrm{C}$ & $\mathrm{C}$ \\
\hline $658-748$ & G-T & A-T & A-T & G-T & G-T & G-T & G-T & G-T & G-T \\
\hline 659-746 & T-A & $\overline{\mathrm{T}-\mathrm{A}}$ & $\overline{\mathrm{T}-\mathrm{A}}$ & T-A & T-A & T-A & T-A & T-A & T-A \\
\hline 660-745 & G-C & G-C & G-C & G-C & G-C & G-C & G-C & G-C & $\mathrm{G}-\mathrm{C}$ \\
\hline 694 & $\mathrm{G}$ & $\underline{\mathrm{A}}$ & $\underline{\mathrm{A}}$ & $\mathrm{G}$ & $\mathrm{G}$ & $\mathrm{G}$ & $\mathrm{G}, \underline{\mathrm{A}}+末$ & $\underline{\mathrm{A}} \S \|$ & $\mathrm{G}$ \\
\hline $838-848$ & C-G & $\overline{\mathrm{C}-\mathrm{G}}$ & $\overline{\mathrm{C}-\mathrm{G}}$ & C-G & C-G & C-G & $\mathrm{C}-\mathrm{G}$ & $\overline{\mathrm{C}}-\mathrm{G}$ & C-G \\
\hline $839-847$ & T-A & T-A & T-A & T-A & T-A & T-A & T-A & T-A & T-A \\
\hline 859 & $\mathrm{C}$ & $\mathrm{C}$ & $\mathrm{C}$ & $\mathrm{C}$ & $\mathrm{C}$ & $\mathrm{C}$ & $\mathrm{C}$ & $\mathrm{C}$ & $\mathrm{C}$ \\
\hline $1003-1037$ & $\mathrm{G}-\mathrm{C}$ & $\mathrm{G}-\mathrm{C}$ & $\mathrm{G}-\mathrm{C}$ & $\mathrm{G}-\mathrm{C}$ & $\mathrm{G}-\mathrm{C}$ & G-C & G-C & $\mathrm{G}-\mathrm{C}$ & $\mathrm{G}-\mathrm{C}$ \\
\hline $1007-1022$ & C-G & C-G & C-G & C-G & C-G & $\mathrm{C}-\mathrm{G}, \underline{\mathrm{C}-\mathrm{T}}$ & C-G, $\underline{\mathrm{C}-\mathrm{T}} \dagger \dagger$ & $\underline{\mathrm{C}-\mathrm{T}} \S \|$ & C-G \\
\hline $1133-1141$ & A-T & $\underline{\mathrm{G}-\mathrm{C}}$ & G-C & $\underline{\mathrm{G}-\mathrm{C}}$ & A-T & A-T & $\mathrm{A}-\mathrm{T}$ & $\mathrm{A}-\mathrm{T}$ & A-T \\
\hline $1134-1140$ & C-G & $\overline{\mathrm{C}-\mathrm{G}}$ & $\overline{\mathrm{C}-\mathrm{G}}$ & $\overline{\mathrm{G}-\mathrm{C}}$ & C-G & C-G & C-G & C-G & $\underline{\mathrm{A}-\mathrm{G}} \#$ \\
\hline
\end{tabular}

* E. coli numbering.

$\dagger$ Terrabacter sp. DDE-1 (GenBank U96645) has A-T instead of G-C at position 140-223, T-G instead of G-C at position 157-164, A instead $\mathrm{G}$ at position 694 and $\mathrm{C}-\mathrm{T}$ instead of $\mathrm{C}-\mathrm{G}$ at position 1007-1022.

\$ Terrabacter sp. DPO 1361 (EMBL Y08853) has G-T instead G-C at position 140-223, T-G instead of G-C at position 157-164, A instead $\mathrm{G}$ at position 694 and C-T instead of C-G at position 1007-1022.

$\S$ Janibacter limosus strain DSM 11140 (EMBL Y08539) has G-T instead G-C at position 140-223, T-G instead of G-C at position 157-164, A instead of $\mathrm{G}$ at position 694 and $\mathrm{C}-\mathrm{T}$ instead of $\mathrm{C}-\mathrm{G}$ at position 1007-1022.

| Janibacter limosus strain DSM 11141 (EMBL Y08540) has A-T instead of G-C at position 140-223, A instead of G at position 694 and C-T instead of C-G at position 1007-1022.

- Sanguibacter keddieii strain NCFB 3025 (EMBL X79450) has C-T instead of C-G at position 1007-1022.

\# Terracoccus luteus strain DSM 44267 (EMBL Y11928) has A-G instead of C-G at position 1134-1140.

Table 6. 16S rDNA nucleotide signatures for Ben 109 ${ }^{\top}$, Ben 110, T1-X7' and members of the family Intrasporangiaceae within the suborder Micrococcineae (Stackebrandt et al., 1997)

\begin{tabular}{|c|c|c|c|c|c|c|c|c|c|}
\hline Position* & Micrococcineae & Ben $109^{T}$ & Ben 110 & $\begin{array}{l}\text { T1- } \\
\mathbf{X} 7^{\mathrm{T}}\end{array}$ & Terrabacter $\dagger$ & $\begin{array}{c}\text { Intrasporangium } \\
\text { calvum }\end{array}$ & Sanguibacter & Janibacter§ & $\begin{array}{c}\text { Terracoccus } \\
\text { luteus }\end{array}$ \\
\hline $66-103$ & A-T & A-T & A-T & A-T & A-T & A-T & A-T & A-T & A-T \\
\hline $70-98$ & $\mathrm{~T}-\mathrm{A}$ & $\mathrm{T}-\mathrm{A}$ & $\mathrm{T}-\mathrm{A}$ & $\mathrm{T}-\mathrm{A}$ & $\mathrm{T}-\mathrm{A}$ & $\mathrm{T}-\mathrm{A}$ & $\mathrm{T}-\mathrm{A}$ & $\mathrm{T}-\mathrm{A}$ & $\mathrm{T}-\mathrm{A}$ \\
\hline $82-87$ & $\mathrm{G}-\mathrm{C}$ & $\mathrm{G}-\mathrm{C}$ & G-C & G-C & G-C & G-C & G-C & G-C & $\mathrm{G}-\mathrm{C}$ \\
\hline $127-234$ & $A-T$ & A-T & A-T & A-T & A-T & A-T & A-T & A-T & A-T \\
\hline 449 & A & A & A & A & A & $\mathrm{A}$ & A & A & $\mathrm{A}$ \\
\hline $598-640$ & $\mathrm{~T}-\mathrm{G}$ & $\mathrm{T}-\mathrm{G}$ & $\mathrm{T}-\mathrm{G}$ & $\mathrm{T}-\mathrm{G}$ & $\mathrm{T}-\mathrm{G}$ & $\mathrm{T}-\mathrm{G}$ & $\mathrm{T}-\mathrm{G}$ & $\mathrm{T}-\mathrm{G}$ & $\mathrm{T}-\mathrm{G}$ \\
\hline $600-638$ & $\mathrm{~T}-\mathrm{G}$ & $\mathrm{T}-\mathrm{G}$ & $\mathrm{T}-\mathrm{G}$ & $\mathrm{T}-\mathrm{G}$ & $\mathrm{T}-\mathrm{G}$ & $\mathrm{T}-\mathrm{G}$ & $\mathrm{T}-\mathrm{G}$ & $\mathrm{T}-\mathrm{G}$ & $\mathrm{T}-\mathrm{G}$ \\
\hline $722-733$ & A-A & A-A & A-A & A-A & A-A & A-A & A-A & A-A & A-A \\
\hline $952-1229$ & C-G & T-A & $\mathrm{T}-\mathrm{A}$ & T-A & $\mathrm{C}-\mathrm{G}$ & $\mathrm{C}-\mathrm{G}$ & $\mathrm{C}-\mathrm{G}$ & $\mathrm{C}-\mathrm{G}$ & $\mathrm{C}-\mathrm{G}$ \\
\hline $986-1219$ & A-T & $\mathrm{A}-\mathrm{T}$ & $\mathrm{A}-\mathrm{T}$ & A-T & A-T & A-T & A-T & A-T & A-T \\
\hline $987-1218$ & A-T & A-T & A-T & A-T & A-T & A-T & A-T & A-T & A-T \\
\hline $1059-1198$ & $\mathrm{~T}-\mathrm{A}$ & $\mathrm{T}-\mathrm{A}$ & $\mathrm{T}-\mathrm{A}$ & $\mathrm{T}-\mathrm{A}$ & $\mathrm{T}-\mathrm{A}$ & $\mathrm{T}-\mathrm{A}$ & $\mathrm{T}-\mathrm{A}$ & $\mathrm{T}-\mathrm{A}$ & $\mathrm{T}-\mathrm{A}$ \\
\hline
\end{tabular}

* E. coli numbering.

$\dagger$ Terrabacter tumescens (GenBank AF005023), Terrabacter sp. DDE-1 (GenBank U96645) and Terrabacter sp. DPO 1361 (EMBL Y08853) were used for comparison.

† Sanguibacter inulinus strain ST-50 (EMBL X79452), Sanguibacter keddieii strain ST-74 (EMBL X79450), Sanguibacter sp. (EMBL Y09657) and Sanguibacter suarezii strain ST-26 (EMBL X79451) were used for comparison.

$\S$ Janibacter limosus strain DSM 11141 (EMBL Y085390) and Janibacter limosus strain DSM 11141 (EMBL Y08540) were used for comparison. 
suggest that strain $\mathrm{T} 1-\mathrm{X} 7^{\mathrm{T}}$ is a representative of another species within the genus Tetrasphaera. This taxonomic proposition is given further support when the 16S rDNA signature positions are considered (Table 5). Thus both Ben $109^{\mathrm{T}}$ and Ben 110 possess TA instead of G-C at position 157-164 as also found in $\mathrm{T} 1-\mathrm{X} 7^{\mathrm{T}}$, A-T instead of G-T at $658-748$ and G-C instead of A-T at 1133-1141. Hence, we propose that Ben $109^{\mathrm{T}}$ and Ben 110 be placed in the same species in the genus Tetrasphaera as Tetrasphaera australiensis sp. nov. and strain $\mathrm{T} 1-\mathrm{X} 7^{\mathrm{T}}$ as Tetrasphaera japonica sp. nov.

It is clear, using the taxonomic scheme of Stackebrandt et al. (1997) for Actinobacteria, based solely on $16 \mathrm{~S}$ rDNA signatures that Tetrasphaera fits readily within the suborder Micrococcineae, even though its signatures do not precisely match those for this group. Thus T-A replaces C-G at position 952-1229. All the other closest related genera (Table 6) show complete agreement with the scheme of Stackebrandt et al. (1997) for this suborder.

However, Tetrasphaera does have multiple mismatches (Table 5) with the signatures considered diagnostic for the family Intrasporangiaceae by Stackebrandt et al. (1997), although Tetrasphaera japonica shows closer agreement (Tables 5 and 6) than Tetrasphaera australiensis (two mismatches compared to four mismatches). Furthermore, Janibacter (Martin et al., 1997), Terracoccus (Prauser et al., 1997) and Sanguibacter (Pascual et al., 1996) also have several mismatches in their signature for the current delineation of the family Intrasporangiaceae (Tables 5 and 6). It is probable that the current classification of this group of bacteria will need modification when more isolates of closely related members of the Actinobacteria are obtained and characterized, and as such should be viewed as preliminary. The recent description of Tessaracoccus (Maszenan et al., 1999a), which also shows considerable departures from this proposal, reinforces this view.

\section{Description of Tetrasphaera gen. nov.}

Tetrasphaera (Te.tra.sphae'ra. Gr. n. tetra four; M.L. fem. n. sphaera sphere; M.L. fem. n. Tetrasphaera, four spherical bacterial cells).

Originates from activated sludge. Cells are Grampositive, aerobic and coccoid in shape $(0.5-1.4 \mu \mathrm{m}$ diam.) occurring singly or in pairs but predominantly as tetrads and in clusters. Cells are non-motile and non-spore-forming. Cultures grow very slowly and utilize a limited number of substrates. Catalasepositive, urease-negative and able to store polyphosphate. Do not produce $\mathrm{H}_{2} \mathrm{~S}$ or indole. Cannot hydrolyse gelatin, but can utilize propionate, acetate, glucose and arbutin. Cell wall peptidoglycan contains meso-diaminopimelic acid $\left(m-\mathrm{A}_{2} \mathrm{pm}\right)$ which characterizes type $\mathrm{A} 1 \gamma$ murein. The major menaquinone is
MK- $8\left(\mathrm{H}_{4}\right)$. Mycolic acids are absent. The $\mathrm{pH}$ range supporting growth is between 6.0 and $8 \cdot 0$. The main cellular fatty acid is iso- $\mathrm{C}_{16: 0}$, and ai- $\mathrm{C}_{17: 0}, \mathrm{i}-\mathrm{C}_{16: 1}$, i$\mathrm{C}_{15: 0}$ as well as $\mathrm{C}_{16: 1}$ are present in smaller amounts. All three have G-C at position 1133-1141 and T-A at position 952-1229. The $\mathrm{G}+\mathrm{C}$ content of the DNA is between 68 and $71 \%$. Phylogenetically, its closest relatives are Terrabacter, Terracoccus, Sanguibacter, Intrasporangium and Janibacter, all in the family Intrasporangiaceae, suborder Micrococcineae. The type species is Tetrasphaera japonica.

\section{Description of Tetrasphaera japonica sp. nov.}

Tetrasphaera japonica (ja.po'ni.ca. N.L. adj. japonica pertaining to Japan, from where the isolate originated).

The morphology, chemotaxonomic properties and phenotypic characteristics are the same as those already described for the genus. This species is weakly catalase-positive. It possesses the respiratory quinones MK-7 $\left(\mathrm{H}_{4}\right)$ and MK-6( $\left.\mathrm{H}_{4}\right)$ in addition to the major menaquinone $\mathrm{MK} 8\left(\mathrm{H}_{4}\right)$ and contains an unknown amino phospholipid. It also possesses $\mathrm{i}-2 \mathrm{OH}-\mathrm{C}_{16: 0}, 2-$ $\mathrm{OH}-\mathrm{C}_{17: 0}, \mathrm{i}-\mathrm{C}_{18: 0}, \mathrm{i}-\mathrm{C}_{18: 1}$ and tuberculostearic acid (TBSA) and lacks both iso- $\mathrm{C}_{14: 0}$ and $\mathrm{C}_{16: 0}$. It can utilize pyruvic acid. The $\mathrm{G}+\mathrm{C}$ content is $71 \mathrm{~mol} \%$. It has G-C at position 1133-1141 and G-C at position $1134-1140$ of its $16 \mathrm{~S}$ rDNA. The type strain, T1-X7 ${ }^{\mathrm{T}}$, has been deposited in the Australian Collection of Microorganisms, University of Queensland, Brisbane, Australia, as strain ACM 5116 ${ }^{\mathrm{T}}$.

\section{Description of Tetrasphaera australiensis sp. nov.}

Tetrasphaera australiensis (aus.tra.li.en'sis. L. nom. fem. adj. australiensis of Australia, from where the isolates originated).

Two strains fit the description of this species based on phylogenetic analysis and phenotypic properties. Both Ben $109^{\mathrm{T}}$ and Ben 110 contain $\mathrm{MK}-8\left(\mathrm{H}_{4}\right)$ as the major menaquinone and $\mathrm{MK}-8\left(\mathrm{H}_{2}\right)$ is present in trace amounts. In addition, strain Ben 110 possesses a large amount of MK-6 $\left(\mathrm{H}_{4}\right)$, while Ben $109^{\mathrm{T}}$ has MK-8 in trace amounts instead. They can both utilize Tween 40 , Tween 80, sucrose, D-trehalose, 3-methylglucose, Dxylose and adenosine- $5^{\prime}$-monophosphate, and have TA at position 157-164, A-T at position 658-748 and A at position 694 of their $16 \mathrm{~S}$ rDNA. Their $\mathrm{G}+\mathrm{C}$ content is $68-70 \mathrm{~mol} \%$. The type strain, Ben $109^{\mathrm{T}}$, has been deposited in the Australian Collection of Microorganisms, University of Queensland, Brisbane, Australia, as strain ACM 5117 ${ }^{\mathrm{T}}$, while strain (Ben 110) is deposited as strain ACM 5118.

\section{ACKNOWLEDGEMENTS}

A.M.M. was supported by a LUPRS and LUOPRS scholarship. This work was supported by a La Trobe University Central Grant and an ARC small grant. We thank Professor H. Trüper for his assistance with naming these isolates. Mrs U. Mendrock (DSMZ) is thanked for her assistance with the DNA-DNA hybridization studies. 


\section{REFERENCES}

Altschul, S. F., Madden, T. L., Schäffer, A. A., Zhang, J., Zhang, Z., Miller, W. \& Lipman, D. J. (1997). Gapped BLAST and PSI-BLAST: a new generation of protein database search programs. Nucleic Acids Res 25, 3389-3402.

Amann, R., Ludwig, W. \& Schleifer, K.-H. (1995). Phylogenetic identification and in situ detection of individual microbial cells without cultivation. Microbiol Rev 59, 143-169.

Amann, R., Lemmer, H. \& Wagner, M. (1998). Monitoring the community structure of wastewater treatment plants: a comparison of old and new techniques. FEMS Microbiol Ecol 25 , 205-215.

Andreasen, K. \& Nielsen, P. H. (1997). Application of microautoradiography for the study of substrate uptake by filamentous microorganisms in activated sludge. Appl Environ Microbiol 63, 3662-3668.

Andrews, K. T. \& Patel, B. K. C. (1996). Fervidobacterium gondwanense sp. nov., a new thermophilic anaerobic bacterium isolated from nonvolcanically heated geothermal waters of the Great Artesian Basin of Australia. Int J Syst Bacteriol 46, 265-269.

Benson, D., Lipman, D. J. \& Olstell, J. (1993). GenBank. Nucleic Acids Res 21, 2963-2965.

Bond, P. L., Hugenholtz, P., Keller, J. \& Blackall, L. L. (1995). Bacterial community structures of polyphosphate-removing and non-phosphate-removing activated sludges from sequencing batch reactors. Appl Environ Microbiol 61, $1910-1916$

Buck, J. D. (1982). Non staining $(\mathrm{KOH})$ method for determination of Gram reactions of marine bacteria. Appl Environ Microbiol 44, 992-993.

Carucci, A., Lindrea, K., Majone, M. \& Ramadori, R. (1995). Dynamics of the anaerobic utilization of organic substrates in an anaerobic/aerobic sequencing batch reactor. Water Sci Technol 31, 35-43.

Cech, J. S. \& Hartman, P. (1990). Glucose induced breakdown of enhanced biological phosphate removal. Environ Technol 11, 651-656.

Cech, J. S. \& Hartman, P. (1993). Competition between polyphosphate and polysaccharide accumulating bacteria in enhanced biological phosphate removal systems. Water Res $\mathbf{2 7}$, $1219-1225$.

Collins, M. D. \& Jones, D. (1980). Lipid in the classification and identification of coryneform containing peptidoglycans based on 2,4-diaminobutyric acid. J Appl Bacteriol 48, 459-470.

Collins, M. D., Dorsch, M. \& Stackebrandt, E. (1989). Transfer of Pimelobacter tumescens to Terrabacter tumescens comb. nov. and Pimelobacter jensenii to Nocardioides as Nocardioides jensenii comb. nov. Int J Syst Bacteriol 39, 1-6.

De Ley, J., Cattoir, H. \& Reynaerts, A. (1970). The quantitative measurement of DNA hybridization from renaturation rates. Eur J Biochem 12, 133-142.

Felsenstein, J. (1993). PHYLIP (Phylogeny Inference Package) version 3.5.1. Seattle: Department of Genetics, University of Washington.

Fernández-Garayzábal, J. F., Dominguez, L., Pascual, P., Jones, D. \& Collins, M. D. (1995). Phenotypic and phylogenetic characterization of some unknown coryneform bacteria isolated from bovine blood and milk: description of Sanguibacter gen. nov. Lett Appl Microbiol 20, 69-75.

Fox, G. E., Wisotzkey, J. D. \& Jurtshuk, P., Jr (1992). How close is close: 16S rRNA sequence identity may not be sufficient to guarantee species identity. Int J Syst Bacteriol 42, 166-170.

Groth, I., Schumann, P., Weiss, N., Martin, K. \& Rainey, F. A. (1996). Agrococcus jenensis. gen. nov., sp. nov., a new genus of actinomycetes with diaminobutyric acid in the cell wall. Int $J$ Syst Bacteriol 46, 234-239.

Hasegawa, T., Takizawa, M. \& Tanida, S. (1983). A rapid analysis for chemical grouping of aerobic actinomycetes. J Gen Appl Microbiol 29, 319-322.

Head, I. M., Saunders, J. R. \& Pickup, R. W. (1998). Microbial evolution, diversity, and ecology: a decade of ribosomal RNA analysis of uncultured microorganisms. Microb Ecol 35, 1-21.

Hiraishi, A., Ueda, Y. \& Ishihara, J. (1998). Quinone profiling of bacterial communities in natural and synthetic sewage activated sludge for enhanced phosphate removal. Appl Environ Microbiol 64, 992-998.

Hucker, G. J. (1921). A new modification and application of the Gram stain. J Bacteriol 6, 396-397.

Huss, V. A. R., Festl, H. \& Schleifer, K.-H. (1983). Studies on the spectrophotometric determination of DNA hybridization from renaturation rates. Syst Appl Microbiol 4, 184-192.

Jahnke, K.-D. (1992). Basic computer program for evaluation of spectroscopic DNA renaturation data from Gilford System 2600 spectrophotometer on a PC/XT/AT type personal computer. J Microbiol Methods 15, 61-73.

Jukes, T. H. \& Cantor, C. R. (1969). Evolution of protein molecules. In Mammalian Protein Metabolism, pp. 21-132. Edited by H. N. Munro. New York: Academic Press.

Kalakoutskii, L. V. (1989). Genus Intrasporangium Kalakoutskii, Kirillova and Krassilnikov 1967, 79 ${ }^{\mathrm{AL}}$. In Bergey's Manual of Systematic Bacteriology, vol. 4, pp. 2395-2397. Edited by S. T. Williams, M. E. Sharpe \& J. G. Holt. Baltimore: Williams \& Wilkins.

Kalakoutskii, L. V., Kirillova, I. P. \& Krassilnikov, N. A. (1967). A new genus of the Actinomycetales -Intrasporangium gen. nov. J Gen Microbiol 48, 79-85.

Kämpfer, P. (1997). Detection and cultivation of filamentous bacteria from activated sludge. FEMS Microbiol Ecol 23, 169-181.

Kataoka, N., Tokiwa, Y., Tanaka, Y., Takeda, K. \& Suzuki, T. (1996). Enrichment culture and isolation of slow growing bacteria. Appl Microbiol Biotechnol 45, 771-777.

Liu, W.-T., Nakamura, K., Matsuo, T. \& Mino, T. (1996). Glycogen accumulating population and its anaerobic substrates uptake in anaerobic-aerobic activated sludge without biological phosphorus removal. Water Res 30, 75-82.

Liu, W.-T., Mino, T., Nakamura, K. \& Matsuo, T. (1997). Internal energy-based competition between polyphosphate- and glycogen-accumulating bacteria in biological phosphorus removal reactors - effect of $\mathrm{P} / \mathrm{C}$ feeding ratio. Water Res $\mathbf{3 1}$, $1430-1438$

Maidak, B. L., Olsen, G. J., Larsen, N., Overbeek, R., McCaughey, M. J. \& Woese, C. R. (1997). The RDP (Ribosomal Database Project). Nucleic Acids Res 25, 109-111.

Martin, K., Schumann, P., Rainey, F. A., Schuetze, B. \& Groth, I. (1997). Janibacter limosus gen. nov., sp. nov., a new actinomycete with meso-diaminopimelic acid in the cell wall. Int $J$ Syst Bacteriol 47, 529-534.

Maszenan, A. M., Seviour, R. J., Patel, B. K. C., Rees, G. N. \& McDougall, B. M. (1997). Amaricoccus gen. nov., a gram negative coccus occurring in regular packages or tetrads isolated from 
activated sludge biomass, and descriptions of Amaricoccus veronensis sp. nov., Amaricoccus tamworthensis sp. nov., Amaricoccus macauensis sp. nov. and Amaricoccus kaplicensis sp. nov. Int J Syst Bacteriol 47, 727-734.

Maszenan, A. M., Seviour, R. J., Patel, B. K. C., Schumann, P. \& Rees, G. N. (1999a). Tessaracoccus bendigoensis gen. nov., sp. nov., a new gram-positive coccus occuring in regular packets or tetrads, isolated from activated sludge. Int $J$ Syst Bacteriol 49, 459-468.

Maszenan, A. M., Seviour, R. J., Pate, B. K. C., Schumann, P., Burghardt, J., Webb, R. I., Soddell, J. A. \& Rees, G. N. (1999b). Friedmanniella spumicola sp. nov. and Friedmanniella capsulata sp. nov. from activated sludge foam: Gram-positive cocci that grow in aggregates of repeating groups of cocci. Int J Syst Bacteriol 49, 1667-1680

Mesbah, M., Premachandran, U. \& Whitman, W. B. (1989). Precise measurement of the $\mathrm{G}+\mathrm{C}$ content of deoxyribonucleic acid by high-performance liquid chromatography. Int $J$ Syst Bacteriol 39, 159-167.

Minnikin, D. E., Alshamaony, L. \& Goodfellow, M. (1975). Differentiation of Mycobacterium, Nocardia, and related taxa by thin-layer chromatographic analysis of whole organism methanolysates. J Gen Microbiol 88, 200-204.

Muyzer, G. \& Smalla, K. (1998). Application of denaturing gradient gel electrophoresis (DGGE) and temperature gradient gel electrophoresis (TGGE) in microbial ecology. Antonie Leeuwenhoek 73, 127-141.

Nakamura, K., Hiraishi, A., Yoshimi, Y., Kawaharasaki, M., Masuda, K. \& Kamagata, Y. (1995). Microlunatus phosphovorus gen. nov., sp. nov., a new gram-positive polyphosphateaccumulating bacterium isolated from activated sludge. Int $J$ Syst Bacteriol 45, 17-22.

Nielsen, A. T., Liu, W.-T., Filipe, C., Grady, L., Jr, Molin, S. \& Stahl, D. A. (1999). Identification of a novel group of bacteria in sludge from a deteriorated biological phosphorus removal reactor. Appl Environ Microbiol 65, 1251-1258.

Nielsen, P. H., Andreasen, K., Wagner, M., Blackall, L. L., Lemmer, L. \& Seviour, R. J. (1998). Variability of the type $021 \mathrm{~N}$ in activated sludge as determined by in situ substrates uptake pattern and in situ hybridization with fluorescent rRNA targeted probes. Water Sci Technol 37, 423-430.

Painter, H. A. (1983). Metabolism and physiology of aerobic bacteria and fungi. In Ecological Aspects of Used-water Treatment, vol. 2, pp. 11-75. Edited by C. R. Curds \& H. A. Hawks. London: Academic Press.

Pascual, C., Collins, M. D., Grimont, P. A. D., Dominguez, L. \& Fernández-Garayzábal. (1996). Sanguibacter inulinus sp. nov. Int J Syst Bacteriol 46, 811-813.

Prauser, H., Schumann, P., Rainy, F. A., Kroppenstedt, R. M. \& Stackebrandt, E. (1997). Terracoccus luteus gen. nov., sp. nov., an LL-diaminopimelic acid containing coccoid actinomycete from soil. Int J Syst Bacteriol 47, 1218-1224.

Randall, A. A. (1994). The effect of substrates chemistry on enhanced biological phosphorus removal, intracellular phosphate form and location, and the resulting population structure of sequencing batch reactors receiving synthetic wastewater. $\mathrm{PhD}$ dissertation, Auburn University, Alabama, USA.

Rees, G. N., Vasiliadis, G., May, J. W. \& Bayly, R. C. (1992). Differentiation of polyphosphate and poly- $\beta$-hydroxybutyrate granules in an Acinetobacter sp. isolated from activated sludge. FEMS Microbiol Lett 94, 171-174.

Schleifer, K. H. \& Kandler, O. (1972). Peptidoglycan types of bacterial cell walls and their taxonomic implication. Bacteriol Rev 36, 407-477.

Schumann, P., Prauser, H., Rainey, F. A., Stackebrandt, E. \& Hirsch, P. (1997). Friedmanniella antarctica gen. nov., sp. nov., an LL-diaminopimelic acid containing actinomycete from Antarctic sandstone. Int J Syst Bacteriol 47, 278-283.

Seviour, R. J. \& Blackall, L. L. (1999). Microbiology of Activated Sludge. Dordrecht: Kluwer.

Siefert, J. L. \& Fox, G. E. (1998). Phylogenetic mapping of bacterial morphology. Microbiology 144, 2803-2808.

Skerman, V. B. D. (1968). A new type of micromanipulator and microforge. J Gen Microbiol 54, 287-297.

Smibert, R. M. \& Krieg, N. L. (1994). Phenotypic characterization. In Methods for General and Molecular Bacteriology, pp. 607-654. Edited by P. Gerhardt, R. G. E. Murray, W. A. Wood \& N. R. Krieg. Washington, DC: American Society for Microbiology.

Stackebrandt, E. \& Goebel, B. M. (1994). Taxonomic note: a place for DNA-DNA reassociation and 16S rRNA sequence analysis in the present species definition in bacteriology. Int $J$ Syst Bacteriol 44, 846-849.

Stackebrandt, E., Rainey, F. A. \& Ward-Rainey, N. L. (1997). Proposal for a new hierarchic classification system, Actinobacteria classis nov. Int J Syst Bacteriol 47, 479-491.

Stead, D. E., Sellwood, J. E., Wilson, J. \& Viney, I. (1992). Evaluation of a commercial microbial identification system based on fatty acid profiles for rapid, accurate identification of plant pathogenic bacteria. J Appl Microbiol 72, 315-321.

Van de Peer, Y. \& De Wachter, R. (1993). TREECON: a software package for the construction and drawing of evolutionary trees. CABIOS 9, 177-182.

Wanner, J. (1994). Activated Sludge Bulking and Foaming Control. Lancaster: Technomic Publishing.

Williams, T. M. \& Unz, R. F. (1985). Isolation and characterization of filamentous bacteria present in bulking activated sludge. Appl Microbiol Biotechnol 22, 273-282.

Winker, S. \& Woese, C. R. (1991). A definition of the domain Archaea, Bacteria and Eukarya in terms of small ribosomal RNA characteristics. Syst Appl Microbiol 14, 305-310.

Yamada, K. \& Komagata, K. (1972). Taxonomic studies on coryneform bacteria. IV. Morphological, cultural, biochemical, and physiological characteristics. J Gen Microbiol 18, 399-416.

Yoshimi, Y., Hiraishi, A. \& Nakamura, K. (1996). Isolation and characterization of Microsphaera multipartita gen. nov., sp. nov., a polysaccharide-accumulating gram-positive bacterium from activated sludge. Int J Syst Bacteriol 46, 519-525. 